\title{
A Street Graph-Based Morphometric Characterization of Two Large Urban Areas
}

\author{
Luca Salvadori $^{1}$, Maria Grazia Badas ${ }^{1} \mathbb{D}$, Annalisa Di Bernardino ${ }^{2}$, Giorgio Querzoli ${ }^{1}\left(\mathbb{D}\right.$ and Simone Ferrari ${ }^{1, * \mathbb{D}}$ \\ 1 Department of Civil-Environmental Engineering and Architecture (DICAAR), University of Cagliari, \\ 09123 Cagliari, Italy; luca.salvadori@unica.it (L.S.); mgbadas@unica.it (M.G.B.); querzoli@unica.it (G.Q.) \\ 2 Physics Department, Sapienza University, 00185 Rome, Italy; annalisa.dibernardino@uniroma1.it \\ * Correspondence: ferraris@unica.it
}

Citation: Salvadori, L.; Badas, M.G.; Di Bernardino, A.; Querzoli, G.; Ferrari, S. A Street Graph-Based Morphometric Characterization of Two Large Urban Areas. Sustainability 2021, 13, 1025. https://doi.org/ $10.3390 /$ su13031025

Academic Editor: Paolo Monti Received: 15 December 2020

Accepted: 17 January 2021

Published: 20 January 2021

Publisher's Note: MDPI stays neutral with regard to jurisdictional claims in published maps and institutional affiliations.

Copyright: (c) 2021 by the authors. Licensee MDPI, Basel, Switzerland. This article is an open access article distributed under the terms and conditions of the Creative Commons Attribution (CC BY) license (https:// creativecommons.org/licenses/by/ $4.0 /)$.

\begin{abstract}
Urban microclimate modelling, both numerical and in the laboratory, has strong implications in many relevant health and life-style management issues e.g., in studies for assessment and forecast of air quality (for both outdoor and, as boundary conditions, indoor investigations), for thermometric trend analysis in urban zones, in cultural heritage preservation, etc. Moreover, the study of urban microclimate modelling is largely promoted and encouraged by international institutions for its implication in human health protection. In the present work, we propose and discuss an adaptive street graph-based method aimed at automatically computing the geometrical parameters adopted in atmospheric turbulent flow modelling. This method has been applied to two real cases, the Italian cities of Rome and Cagliari, and its results has been compared with the ones from traditional methods based on regular grids. Results show that the proposed method leads to a more accurate determination of the urban canyon parameters (Canyon Aspect Ratio and Building Aspect Ratio) and morphometric parameters (Planar Area Index and Frontal Area Index) compared to traditional regular grid-based methods, at least for the tested cases. Further investigations on a larger number of different urban contexts are planned to thoroughly test and validate the proposed algorithm.
\end{abstract}

Keywords: urban climate; street canyon; street-based morphometry; air quality

\section{Introduction}

\subsection{Symbols and Acronyms}

As the target of this paper is to present and test a novel street graph-based grid method to automatically compute the geometrical parameters adopted in numerical and laboratory modelling of atmospheric turbulence (and to compare it with previous method based on regular grids), first of all, in this paragraph we present a list of the main parameters and symbols employed hereafter to describe the geometrical features of the urban areas. Given an example building, as depicted in Figure 1, its total pertinence area $\left(A_{T}\right)$ is shaded in green and its planimetric area $\left(A_{P}\right)$ is shaded in orange. The red line denotes the width of a typical urban canyon $\left(W_{C}\right)$ and the blue one indicates a building width $\left(W_{B}\right)$. Assuming a wind direction (in the example NW, showed by the large blue arrow, U), it is possible to define the building width projected on a normal-to-the-wind plane $\left(L_{B}\right)$, which is drawn in yellow in the figure. The other relevant parameters are:

- $H$ : Average buildings height;

- $\quad A R c$ : Canyon Aspect Ratio, i.e., ratio of canyon width $W_{C}$ to buildings height $H$;

- $A R b$ : Building Aspect Ratio, i.e., ratio of the width $W_{B}$ to the height of buildings of the canyon $H$;

- $\quad \lambda_{p}$ : Planar Area Index, i.e., ratio of planar area covered by buildings $A_{P}$ to total extension planar area considered $A_{T}$;

- $\quad \lambda_{f}$ : Frontal Area Index, i.e., ratio of building frontal area projected on the normal plane of a certain direction $\left(A_{F}\right)$ to total extension planar area considered; 
- $\overline{\lambda_{f}}$ : wind direction-averaged Frontal Area Index;

- $\lambda_{\mathrm{f}(\mathrm{dir})}: \lambda_{f}$ calculated on the prevalent wind direction.

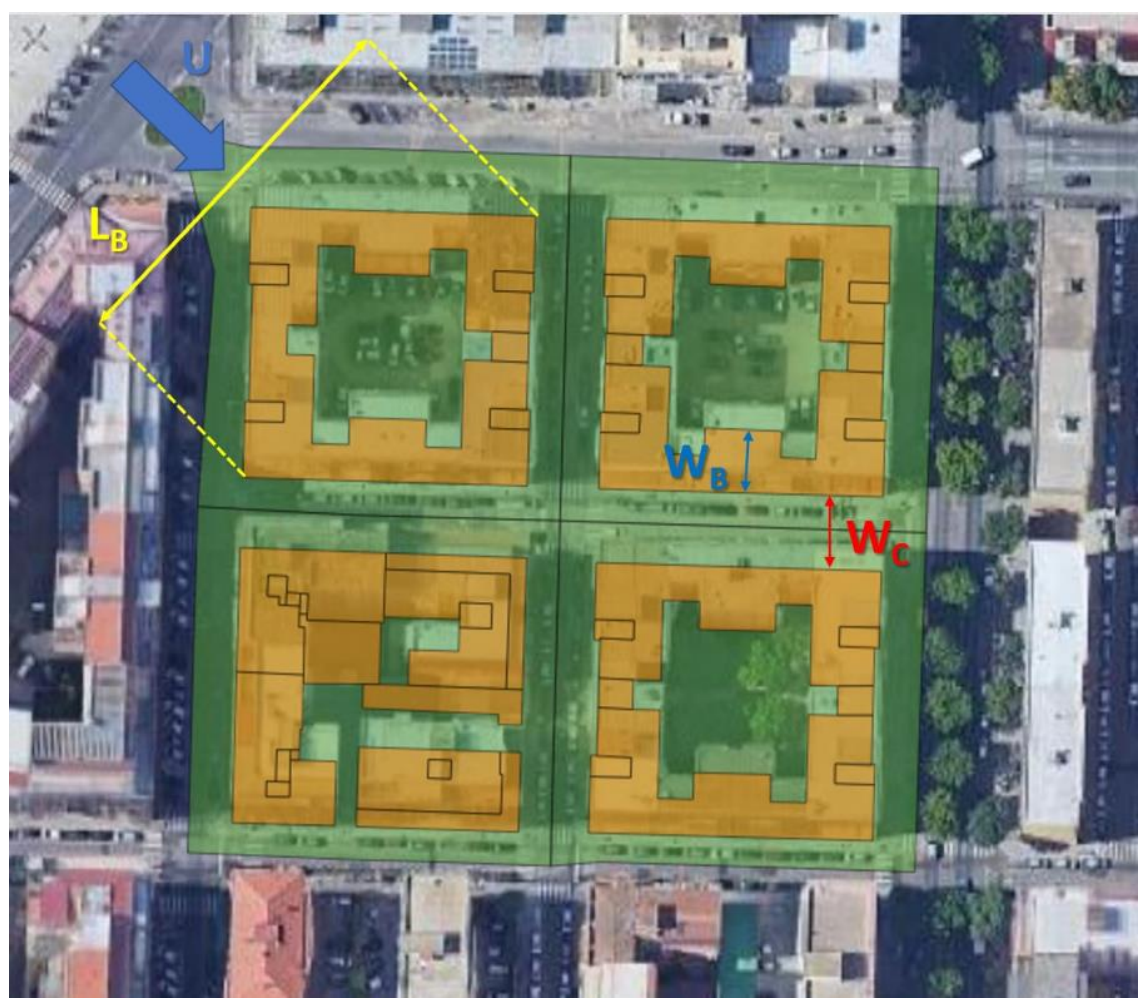

Figure 1. Schematization of main parameters in real, urban texture; $U$ indicates wind direction, $L_{B}$ the building width projected on the plane normal to $U, W_{B}$ is the building width and $W_{C}$ the canyon width, green area indicates the building pertinence area $A_{T}$ and orange areas the building planimetric areas $A_{P}$.

\subsection{State of the Art and Targets}

Many important challenges of our days are strongly linked to urban microclimate modelling and, in particular, to the aerodynamic properties of urban areas: as a consequence of various types of emissions, urban environment can respond in different manners depending on its specific characteristics (Lou et al. 2016 [1]). Uncontrollable variables (such as wind direction and speed, air temperature, and humidity) and human-related conditions (in particular, urban characteristics, and landscape) should be taken into account to correctly plan and manage urban environment (Chiri et al. 2020 [2]). Thus, urban morphology hallmarks acquire relevance in a general way and in a broad range of sectors (Kent et al. 2019 [3]), being involved in a circular process: beyond their effects in urban air quality (both outdoors, as in Peng et al. 2017 [4]; Shen et al. 2017 [5]; Chan and Liu 2018 [6]; Shi et al. 2018 [7], and indoors, as in Pelliccioni et al. 2020 [8]). Moreover, they are also crucial for the reliability of urban aerodynamic modelling in forecast codes (e.g., to predict pollutant dispersion and urban microclimate in the built environment). Nowadays, air quality modelling is largely promoted and encouraged by local and international institutions (see, e.g., the Directive 2008/50/EC of the European Parliament about the air quality in Europe [9]) and, as a consequence, urban surface parametrization is fundamental in air quality assessing and forecasting models but still technically demanding (Liu et al. 2018 [6]). Primarily, a well-defined set of $\lambda_{p}$ and $\lambda_{f}$ values for an investigated urban site is required for a better comprehension and modelling of the vertical wind profile in the studied area. Secondly, the study of the best use of morphometric parameters for the definition of fluid dynamic roughness length $\left(z_{0}\right)$ and zero-plane displacement height $\left(z_{d}\right)$ is currently ongoing (Kent et al. 2018 [10]). Moreover, this parametrization is needed both 
for urban Computational Fluid Dynamics (CFD) simulations (Blocken 2015 [11]) and for mesoscale numerical weather prediction systems (e.g., Weather Research and Forecasting model, WRF), as described in Skamarock et al. (2008 [12]).

On the one hand, the computation of $z_{0}$ is important in CFD for a realistic simulation of the Atmospheric Boundary Layer (ABL) flow in the computational domain. The lack of site-specific information forces to rely on land-use based $z_{0}$ individuation through specific tables, as those defined by Wieringa (1992 [13]) or by Grimmond and Oke (1999 [14]). The characterization of the boundary zone, which encloses the computation domain, in terms of roughness length $z_{0}$ may also allow to avoid the direct implementation of building geometries for large extension, obtaining good results in comparison with simulations employing a detailed building description (Liu et al. 2018 [5]).

On the other hand, the importance of a detailed parametrization of urban canopies has been demonstrated for mesoscale modelling (e.g., Martilli et al. 2002 [15]; Salamanca et al. 2011 [16]). The urban surface characterization, as defined by Stewart and Oke (2012 [17]), is currently widely used and it is gathered in the World Urban Database Access Portal and Tools (WUDAPT) (Demuzere et al. 2019 [18]). According to this philosophy, a parametrization of urban surfaces is required to sort them into homogeneous Local Climate Zones (LCZs), each one linked to a specific range of values of the required descriptive parameters, both in terms of building geometry and thermodynamic properties of the materials. For a complete overview, see Stewart and Oke (2012 [17]), while for a general discussion on the application of the mentioned classifications see Ching et al. (2018 [19]).

Regarding the urban morphometric calculation for the determination of $z_{d}$ and $z_{0}$, several questions still remain open since the first reviews of different authors' experiences (Grimmond and Oke 1999 [14]). Firstly, as described above, a general lack in knowledge about which values of the fluid dynamic parameters to associate to specific urban texture can be detected. In particular, the method for the determination of $z_{0}$ is still an open issue and still it is often necessary to use quali-quantitative associations between the urban zone description and the related parameter value, or rule of thumb methods (Garuma 2018 [20]). Otherwise, in case of Digital Elevation Models (DEMs) and/or other urban texture digital information, it is possible to derive morphometric parameters with accurate calculation, e.g., based on the building height data for the site. Moreover, this kind of computation can be automatized and, therefore, extended to large urban areas. Evidences reported in Leo et al. (2018 [21]) highlight that the main topics and the leading questions are roughly the same as those described in Badas et al. (2019 [22]), where morphometric and $z_{d}, z_{0}$ definition for different urban areas as obtained by Ratti et al. (2002 [23]) are compared. More specifically, investigations on Oklahoma City were conducted considering its urban map and a hypothetical wind direction. Authors suggest the possibility of a planimetric sub-division based on the ratio between mean building height $\left(H_{m}\right)$ and maximum building height $\left(H_{\max }\right)$, evaluated along two principal directions, $\mathrm{x}$ and $\mathrm{y}$ (where $\mathrm{x}$ is the considered wind direction and $y$ the perpendicular direction). Apparently, zeros of this function may rapidly allow to detect a certain number of sub-matrixes, which represent single buildings or small group of buildings, and to define a grid on the urban area. Finally, it is possible to associate a morphometric (or fluid dynamic) parametrization to every grid cell. However, if the interest is focused along a direction not parallel to main roadways axes, two main obstacles arise. Firstly, the described $H_{m} / H_{\max }$ analysis becomes impossible, just like it happens to any different, irregular urban texture, as many of European ones, where street axis orientation, even in small areas, may be much more complex than a grid of perpendicular or parallel roads. The second problem refers to the distortion of $\lambda_{f}$ values when applying a regular square grid subdivision to "chaotic" urban arrangements, due to unavoidable geometric overestimation of the parameter along diagonal directions, as shown in Badas et al. (2019 [22]).

Regarding mesoscale numerical weather prediction systems, the definitions given in Stewart and Oke (2012 [17]) provide 17 homogeneous classes, 10 for urban texture and 7 for natural background and rural zones. Instead of considering a built-in model 
parametrization and classification or other less specific morphological feature descriptors, a better result in model predictions can be reached, for instance for wind velocity modelling $10 \mathrm{~m}$ above the ground, using the information included in the WUDAPT dataset (Pellegatti Franco et al. 2019 [24]). WUDAPT can be defined as a sort of crowdsourcing for the definition of urban area mesoscale parameters; in fact, it involves a group of local experts (it may be composed of professionals as architects, urban planners, or volunteers), who can provide information on urban texture classification, construction materials, and roadway structures of a specific urban zone; moreover, WUDAPT can manipulate image data. Collected information is useful for the subsequent high-resolution satellite image recognition; in fact, the workflow for urban area classification firstly consists of the choice of Training Areas (TAs), chosen by the aforementioned groups of local experts, and then into the detailed characterization of these areas (Bechtel et al. 2019 [25]). However, authors suggest further possible improvements, in particular in terms of LCZs extrapolation and transferability to different contexts from the ones where they were firstly derived (Kaloustian et al. 2017 [26]). Even if WUDAPT available dataset allows a good urban surface characterization that leads to appreciable modelling results and shows adaptability (e.g., in terms of parameters values interpolation, see Zonato et al. 2020 [27]), a site-specific urban characterization still may help for the urban surface classification purpose. In fact, to obtain the so-called Level 0 data, the individuation of TAs is based on the capability of local community to well recognize the main features of the urban environment into TAs: the following process of classification of other site areas is strongly influenced by this first step. It is necessary to consider that satellite image spectral signatures can differ across the world, so the required TAs data are forced to be site-specific, and is usually acquired by the volunteer local experts (Bechtel et al. 2019 [25]); this means that local training data and knowledge of the local urban structures are a necessity (Bechtel et al. 2015 [28]).

The principal aim of the paper is to propose, test, and discuss a new automatic method for the computation of the geometrical parameters needed for the description of urban areas in numerical and laboratory modelling of atmospheric turbulent flows. The method relies on an adaptive street graph-based morphometric characterization: starting from largely available datasets of building height data and a street graph, we show the possibility to derive specific morphometric values and, therefore, to potentially derive results on any area where data on building height are available. As shown in Section 5, the street graphbased method allows to identify the buildings without any artificial or user-based choice of the regular grid size of and, consequently, to achieve a better accuracy than traditional regular grids. The main idea behind the proposed procedure is, therefore, to automatically identify the street graph and, consequently, the single building or block: in this way, the object of the morphometric analysis is its natural basic component instead of arbitrarily grouping and partially decomposing them into each square of a grid. In this way, it is possible to accurately calculate morphometric (and so fluid dynamic) parameters for every block and to classify different values depending on the zone of interest. Moreover, it is also possible to derive canyon parameters for every street canyon and to compute site-specific statistics. The higher accuracy in the obtained parameters can be very useful for the scientific community working on the numerical and/or laboratory modelling of atmospheric turbulence. Regarding the numerical simulations, in the mesoscale (e.g., Weather Research and Forecasting model, WRF [12]) and microscale (e.g., ANSYS-Fluent [29]) numerical models for meteorological and fluid dynamics characterization of urban areas, the geometric parameters under consideration are key factors for the correct representation of turbulence in complex areas. Regarding the laboratory simulations, they require detailed information about $H, \lambda_{p}$ and $\lambda_{f}$, as these parameters determine the flow regime in the urban canyon and in the roughness sublayer, governing the ventilation and, consequently, the exchanges of mass and momentum between the pedestrian area and the overlying flow (e.g., Di Bernardino et al., 2018 [30], Garau et al., 2018 [31] and Badas et al., 2021 [32]). Moreover, those parameters are peculiar of each urban area and, consequently, they have to be properly chosen accordingly to the urban area under investigation: for instance, most 
of the old town centers of European cities are characterized by narrow street canyon, i.e., $A R c$ smaller than 1 ([33]). In addition, the flow and the turbulence features over buildings depend also on $A R b$ : see, for instance, [34] and [35] and references therein.

\section{Case Study}

As stated in the previous section, the main target of the paper is to propose, test, and discuss a new automatic method, described in detail in Section 3, for the geometrical description of urban areas needed for the numerical and laboratory simulation of atmospheric turbulent flows. The proposed adaptive street graph-based method for the morphometric characterization of urban areas was applied to two actual urban areas, in order to compare the results with the ones from traditional regular grid size methods. We considered two urban areas in Italy (Figure 2): a central portion of Rome, parted by its historical districts, and a central portion of the city of Cagliari, parted in its central neighborhoods.

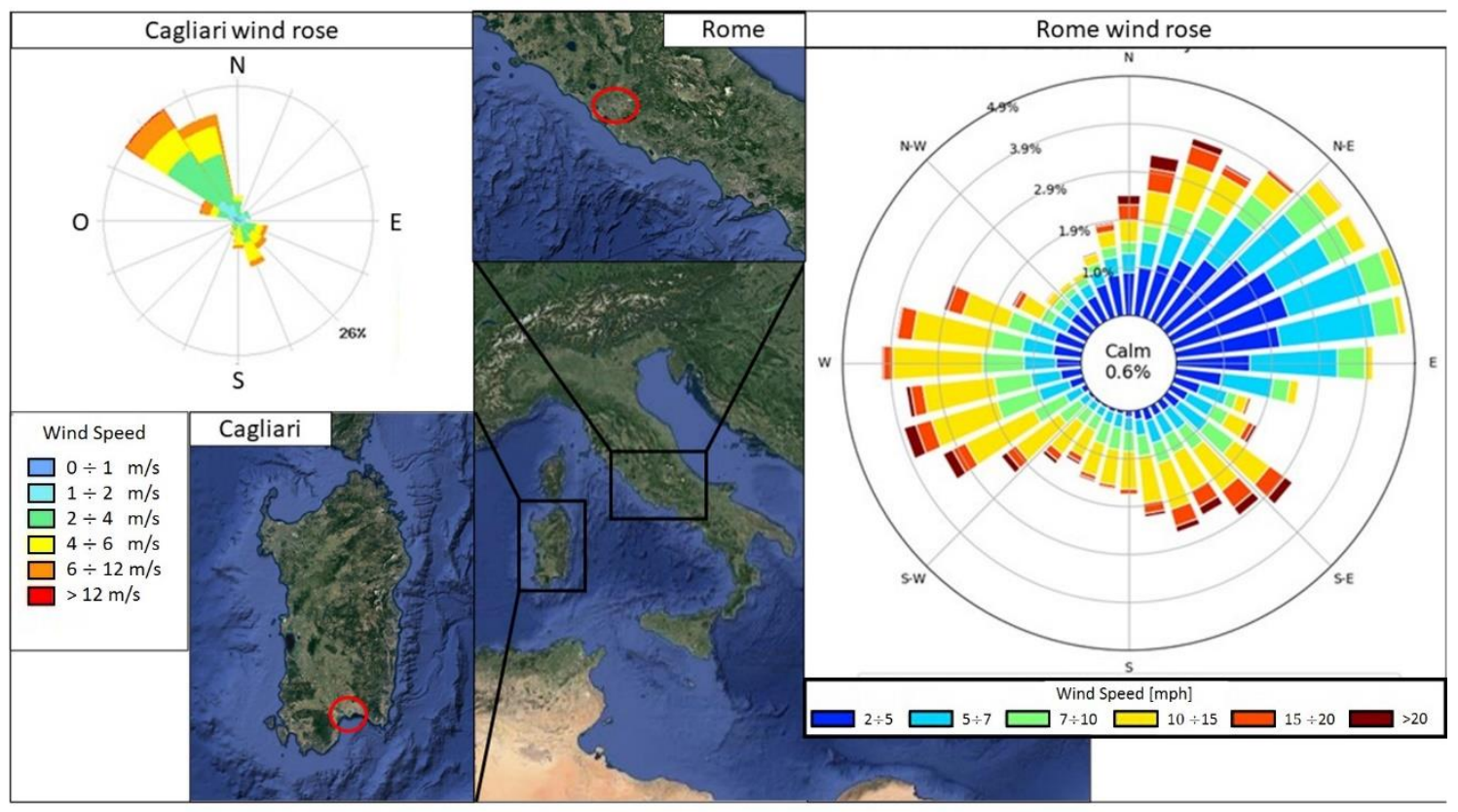

Figure 2. Geographic framing of case studies and related wind roses.

This choice was not random: even if, globally, the bounding of the area of the city of Rome can be dated at the Ancient Roman Age, its districts were involved, time after time, in a controlled urban planning process and building remake, which gave to the area a large variability in form and architectural typology. Analogue considerations can be carried out for Cagliari: historical areas are included, even if with post-modifications as well as recent restoration projects (e.g., immediately post World War II). This inhomogeneity allows, even if involving only two cities, the analysis of a large number of morphometric typologies, and the detection of some site specificities.

To compute the wind direction dependent parameter $\lambda_{f(d i r)}$, it is important to know the anemometric behavior in the two areas. For the city of Rome, we considered the $\mathrm{W}$ provenience, one of the prevalent wind directions in the zone, especially for spring-summer months [36]; for the city of Cagliari we considered the NW provenience, i.e., the dominant wind [37] (see Figure 2).

\section{Methods}

\subsection{Data Description}

As a first step, we prepare and pre-process an initial dataset: mainly, the building heights and, if available, the local street graph. For both Rome and Cagliari, building height data are available on open source sharing institutional sites, while street graph data 
can be obtained in the same platforms or through the OpenStreetMap service. Hereafter, a synthetic description of the initial data for regular and irregular grids used in calculations is given, as well as a discussion about the main differences between the two investigated zones (in Section 3.2). For the elements of the regular grid, we have chosen $100 \mathrm{~m} \times 100 \mathrm{~m}$ squares, as a consequence of a previous study ([22]) whose results showed that, both for $\lambda_{p}$ and $\lambda_{f}$, this size gives a more realistic representation in comparison with smaller element grids. On the other hand, it has been chosen to not exceed that dimension, according to what suggested by other case studies in literature (for a more detailed description of the applied general method, see Badas et al. 2019 [22] and Salvadori et al. 2019 [38]). The total grid element number for the street graph-derived grids is 334 for Cagliari and 4090 for Rome. The total grid element number for the regular grids is 436 for Cagliari and 1678 for Rome.

\subsection{Main Differences between the Two Investigated Areas}

The first basic difference between the two investigated areas is the street graph-based grid texture, as briefly described in the previous section. In fact, notwithstanding the larger extension of the Rome portion compared to the Cagliari one and the obvious larger number of elements both for regular and for adaptive grid, while Rome shows an increase of elements number switching from regular to adaptive grid, for Cagliari an opposite behavior can be detected. This can be explained keeping in mind that the street graph derived grid elements are defined by the local closed polygons formed by street axis: this means a link between its shape and the main street configuration but not necessarily a relation with the effective geometric distribution of built and non-built environment. In fact, two types of distortion have to be considered: the possible absence of street elements for particular areas where pairwise distances between buildings are important, which can lead to the above-described paradox, and the unavoidable errors in the initial data (e.g., imprecise localization of streets, improper axis classification with multiple counts for large streets, etc.). To minimize the second type of error, we pre-processed the data, deleting or modifying non-consistent vector elements; on the other hand, the first kind of error underlines the importance of considering site specificities.

As a consequence of the above discussion, Cagliari and Rome show a different probability density function (pdf) of block areas, as shown in Figure 3.

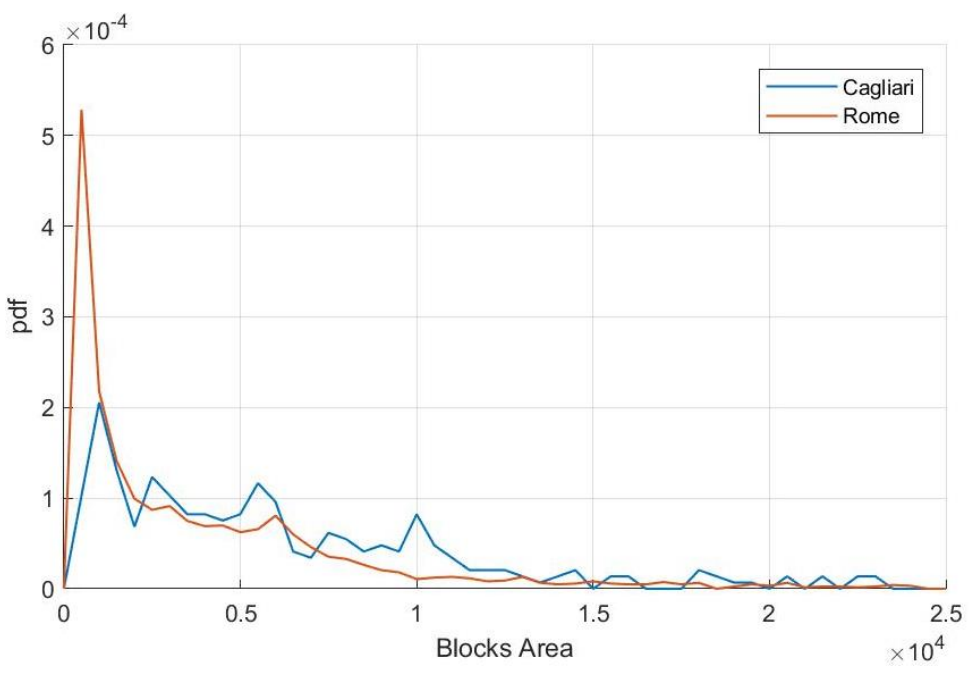

Figure 3. Probability density function of block areas for the two case studies (areas in $\mathrm{m}^{2}$ ).

Rome presents a larger number of small areas, referring to block partition, and this fact has an important impact on $\lambda_{p}$ and $\lambda_{f}$ calculation and statistics. For the sake of clarity, this may depend also on the type and shape of the street graph data used to create the blocks for the irregular grid, rather than on a real different urban texture. In fact, even if peculiar 
elements are identified (e.g., the inner-city river stretch), the effect of residuals of the second type of distortion in street graph may play a role, and arbitrary smaller zones are often found even after the post-processing phase. In order to overcome this discrepancy, here we do not consider the elements with an area smaller than $500 \mathrm{~m}^{2}$ (i.e., the hypothetical minimum realistic block area) and these values are excluded from the pdf shown in Figure 3.

\subsection{Raster Data Treatment and Morphometric Computation}

As a consequence of what is reported in Section 3.2, namely the uncertainties in generalization of grid definition for morphometric analysis, we tested different methods to define the street graph-based grids. As a first analysis, we tried to improve the typical parameter calculation reported in Ratti et al. 2006 [39] and in Di Sabatino et al. 2010 [40], considering a street graph derived adaptive grid.

As mentioned in Section 3.1, for a widespread computation of $H, \lambda_{p}$, and $\lambda_{f}$ a discretized information about building heights is generally needed: these kinds of data are usually achievable in Digital Elevation Models (DEMs), which are cast as simple computertreatable matrixes, and where every matrix value represents the height of a specific terrain point. More specifically, often height information on urban areas is available in a twofold nature: in fact, it is required to manage the Digital Terrain Model (DTM) of the geographic area of interest, which reports ground heights in a topographic sense, and the Digital Surface Model (DSM) of the city or the portion of city under investigation. The latter contains information about heights in a more general way, meaning the inclusion of two main kinds of the motionless objects frequently found on urban surfaces, i.e., buildings and vegetation (even if in this study the contribution of the vegetation was neglected). Clearly, city building heights are obtained by difference between the two mentioned datasets. It is possible to associate to a certain DEM a reference coordinate system and, therefore, each matrix point is uniquely identified through a reference couple in a chosen coordinate system. Thus, it makes sense to associate to raster data even any sort of vectorized dataset, e.g., street graph information, and it is possible to work on their combination. Figure 4 shows what was just described. An example block is indicated, too, and will be recalled in the following description. Heights are reported on a grey scale, that assigns clearer colors to higher values, and street graph vector data are represented by red lines. All the non-building pixels were imposed to a value equal to zero, supposing that every object of less than $2 \mathrm{~m}$ height is not a building, as highlighted by the first inflection of values in the histogram of heights in Figure 5.

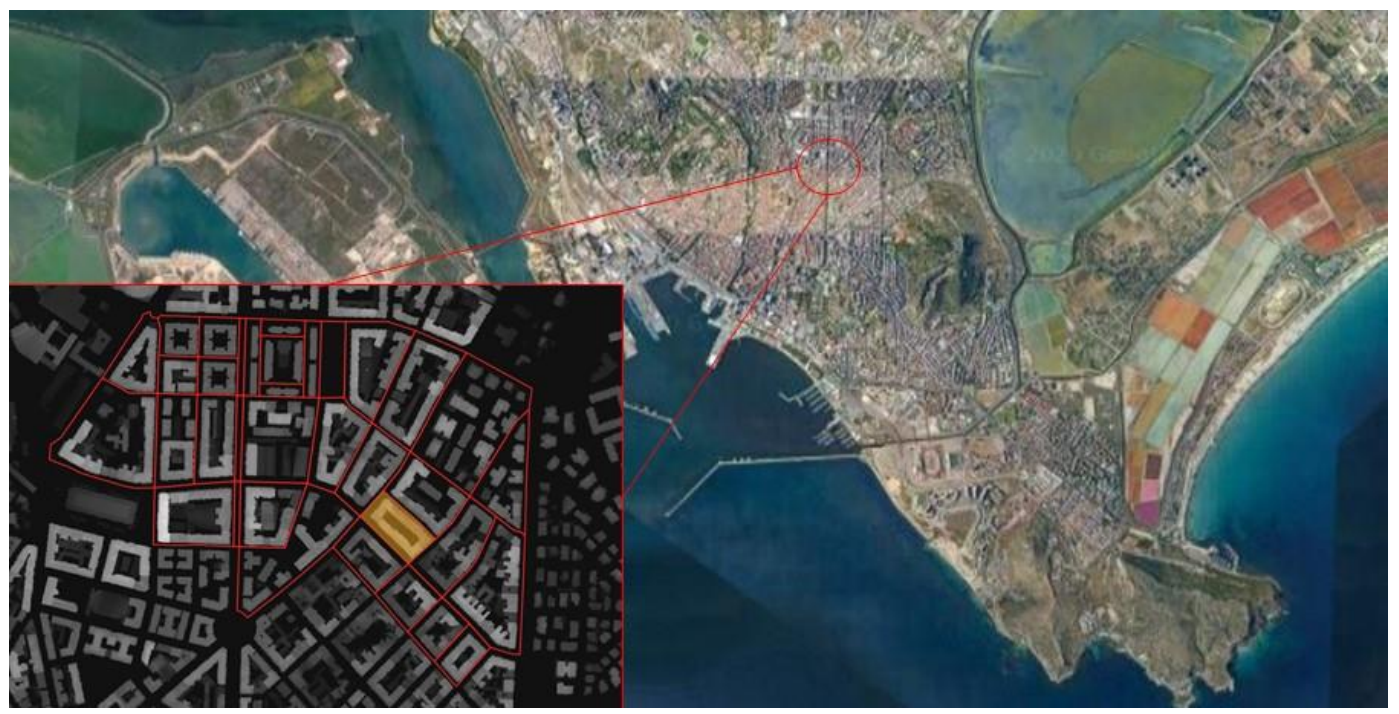

Figure 4. Urban texture sample of Cagliari city. Both raster data and vector data are included, as described in the text. Greyscale represents height values, street graph is reported in red. The example block is highlighted in orange. 


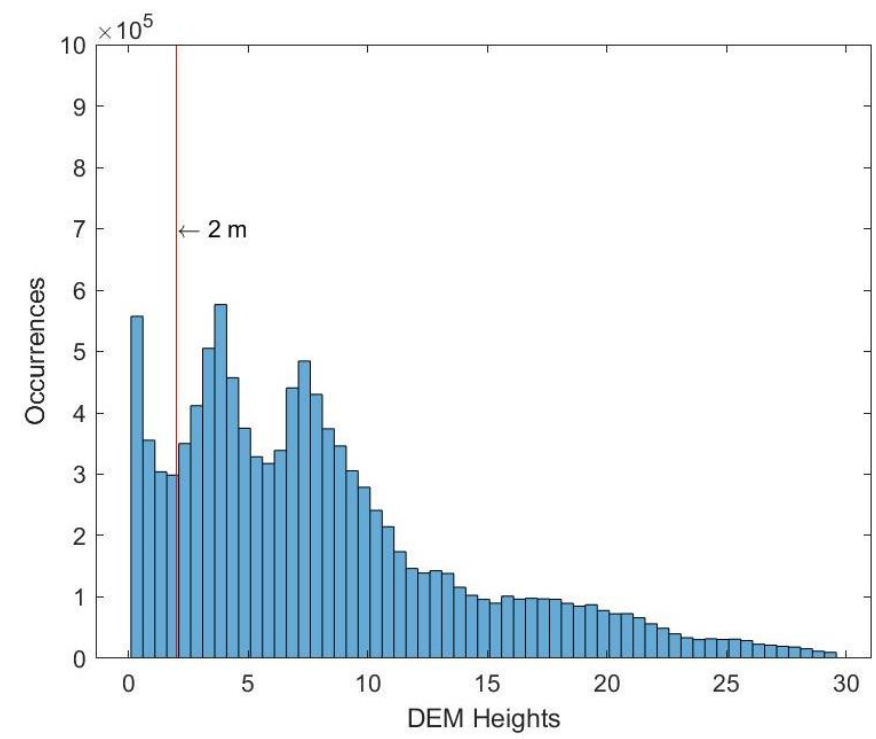

Figure 5. Histogram of height values for Cagliari. First inflection at $2 \mathrm{~m}$ is considered as the partition point between buildings and other city objects. DEMs heights in $\mathrm{m}$.

A brief description of the designed procedure to derive morphometric parameters will be now given. Even if fundamental steps of the method are exactly the same for every shape of grid, here we refer to the street graph-derived grid, due to what discussed in Section 3.2. Depending on street graph vector data quality and accuracy, often blocks may include one single building or a small group of buildings. Referring to Figure 4, any polygon formed by the street graph can be taken as a region of interest. In Figure 4, the position of an example block (in orange) is also shown, which will be considered for the following discussion. Figure 6 represents the workflow to calculate the parameter set for each block. We start from the situation depicted in Figure 6a. At first it is necessary to purge the matrix from other block contributes: as a consequence of geo-localization, this is quite immediate, and every pixel that falls outside the polygon defined by the street graph cycle is set to 0 . So, we obtain the result shown in Figure $6 \mathrm{~b}$, and it is possible to calculate $H, \lambda_{p}$, and $\lambda_{f}$ in the needed direction. $A_{T}$ is the area within the block, i.e., within the red polygon.

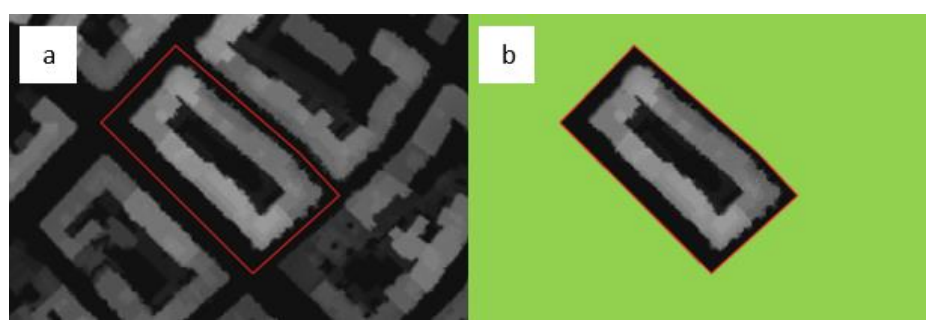

Figure 6. Image processing for parameters calculation; (a) focus on an example block to be considered; (b) isolation of block to make possible to detect its own height values, building cells, and terrain cells (inside the red line). Green area is the excluded one; values inside the red line are the considered ones.

Once the area to be analyzed is chosen (see for example Figure $6 b$ ), recalling the definitions given in Section 1.1, $\lambda_{p}$ is immediately found as follows:

$$
\lambda_{p}=\frac{A_{P}}{A_{T}}=\frac{n_{p b}}{n_{p t}}
$$

where $n_{p b}$ is the number of pixels covered by buildings (i.e., in this context, the number of non-zero values in the matrix) and $n_{p t}$ the total number of pixels inside the polygon. 
A more precise differentiation is needed both for the mean height $H$ and for the frontal area index $\lambda_{f}$. There are different interpretations of the $H$ definition and computation (Ratti et al. 2002 [23]); here we consider the planimetric one, i.e., a simple averaging of the non-zero values included in the studied area, through the following equation:

$$
H=\frac{\sum h_{i}}{n_{p b}}
$$

where $h_{i}$ is the height value that competes to each raster cell.

Instead, $\lambda_{f}$ is unequivocally a directional parameter. Thus, along a certain direction, the first step consists to rotate the raster data to fit wind provenience direction and to obtain a new matrix. After the conclusion of this procedure, for $\lambda_{f}$ calculation it is sufficient to project building frontal area on a plane perpendicular to the investigated direction. Having the height representation matrix, that means to find each column maximum value, then to sum the contributes. So, it is possible to calculate $\lambda_{f}$ as:

$$
\lambda_{f}=\frac{A_{F}}{A_{T}}=\frac{\sum h_{m j}}{n_{p t} d x}
$$

where $h_{m j}$ is the maximum value along the $j$-th column of the rotated matrix, and $d x$ is the length of each pixel side. Note that, because of symmetry properties, it is possible to compute just a half of the chosen directions, if evenly distributed on $360^{\circ}$, saving computational resources and time.

\subsection{Computation of the Aspect Ratios for Canyon Representation}

As previously stated, an urban canyon characterization has been conducted as well. This task requires a knowledge of the orientation and the geometric arrangement of buildings and of the free space between them, i.e., the mutual distance between buildings and the facade height. As the street graph identifies, in most cases, the dividing line between buildings or other urban structures, it can be considered as the basic information to detect canyon parameters. In fact, starting from the street graph, it is possible to define the leading feature of an urban canyon (in most cases, it evenly parts the canyon longitudinally), and the use of a combination of geographic-vectorial and raster-based information allows the extrapolation of a statistic of the buildings' heights (on both canyon sides) and of the mutual building distance, along the main direction of the canyon. Figure 7 shows the basic elements of this analysis. As for morphometric parameters, DSMs provide rasterized data of the building heights. It is immediate to calculate zonal statistics of heights, having available buildings contour vector data, using any GIS support; otherwise, it is possible to obtain these kinds of data starting from buildings' DSM. Choosing an interval, several points along each specific canyon feature can be taken to build transverse sections, and so to collect detailed information on building heights and street width. The considered height for canyon analyses is different from the one used for morphometric classification. As a first step, it is possible to associate to every building polygon the average height value of those that fall within the polygon. So, for every section along a street canyon, the height of the intersected polygons (one on the left and one on the right) can be identified, and the height in that section can be defined as follow:

$$
h_{s e c}=\frac{1}{2}\left(h_{p l}+h_{p r}\right)
$$

where $h_{s e c}$ is the height associated to the section, $h_{p l}$ and $h_{p r}$ are the heights corresponding to the polygon on the left and on the right with respect to the street axis. 


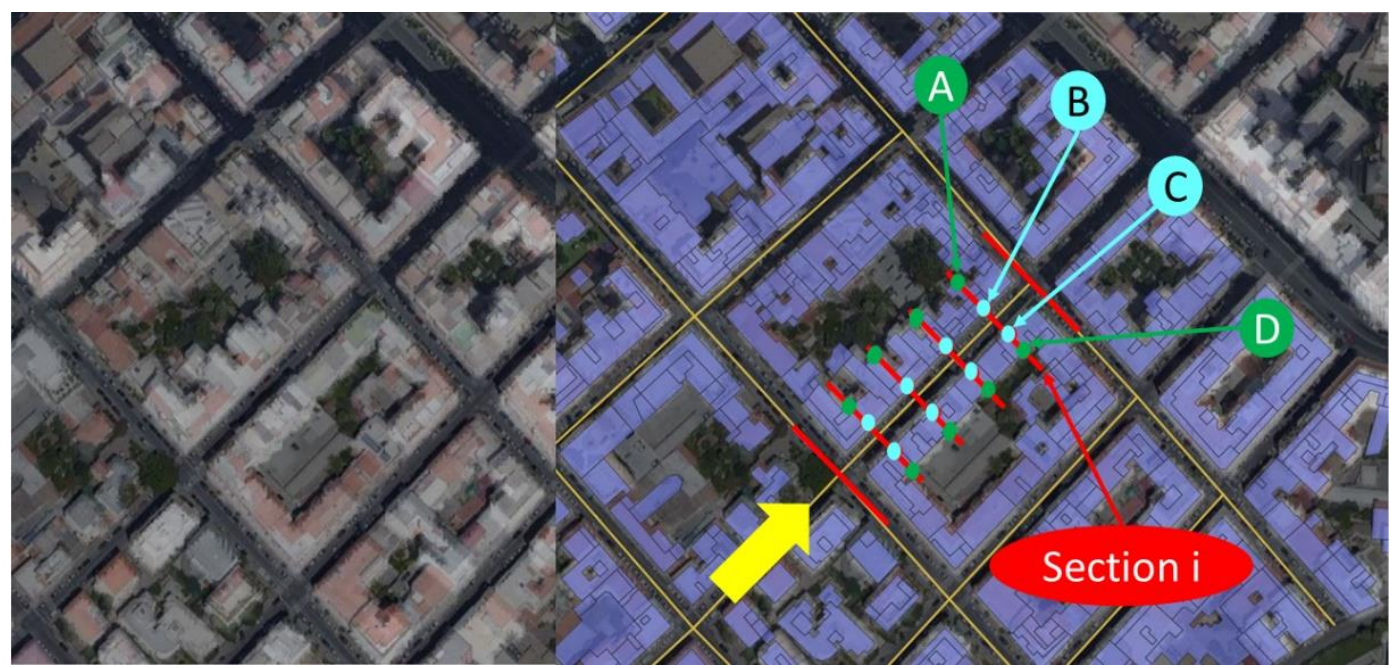

Figure 7. An example of urban canyon features detection for aspect ratio calculations. On the left, the overlap of building heights raster data on Google Satellite image; on the right, street graph (thin yellow lines), canyon transvers sections (thick red lines), and building vector data (semi-transparent blue polygons) are added. Cian points (e.g., B and C) indicate nearest intersections between canyon sections and buildings, green points (e.g., A and D) most distant intersections. Other details in the text.

It is also possible to determine the coordinates of the intersections between the sections and the building polygons: in fact, the building polygon nearest point can be detected, with respect to the street axis, as well as the farthest one, defined as the one that demarcates the building continuity interruption (i.e., the building end wall or the presence of a courtyard), and this can be done for both sides of the street canyon. Referring to Figure 7, along the direction shown by the yellow arrow and taking into account the highlighted "section i", it is possible to automatically calculate the canyon width $W_{C}$ as the distance between $B$ and $\mathrm{C}$, the building width $\left(W_{B}\right)$ on the left as the distance between $\mathrm{A}$ and $\mathrm{B}$ and the building width on the right as the distance between $C$ and $D$; the building width is the average of the lasts.

Combining these quantities, $A R c$ and $A R b$ can be calculated for each sampling section and so for the considered canyon and, for extension, for every canyon in the studied area. So, one of the advantages of the methodology is that it allows an automatic identification of the street canyons and a straightforward calculation of the street canyon features. This is particularly relevant, for instance, when the characteristics of the street canyons to simulate in laboratory or numerical experiments have to be chosen.

\section{Results and Discussion}

This section is organized as follows. In Section 4.1, the spatial distribution and probability density functions of $\lambda_{p}$ and of wind direction-averaged $\overline{\lambda_{f}}$, computed via both the adaptive street graph-based method and a regular grid one, are shown; the results from two grids are then compared and the capability of the methods to identify the single building blocks and their features is discussed. Section 4.2 is dedicated to the results regarding $\lambda_{f}$ as a function of the wind direction, again with a comparison between the adaptive street graph-based grid results and the regular grid ones. In Section 4.3, the Aspect Ratios $A R c$ and $A R b$ computed with the street graph-based grid are shown, with the target to highlight some site-specific features and the need to identify accurate values for these parameters, in particular for studies at the scale of a specific site.

In Table 1, the numbers used to identify the districts of Cagliari and Rome on Figure 8, 10 and 12-15 are listed. On the same Figures, the yellow line indicates the district delimitation. 
Table 1. The investigated districts of Cagliari and Rome.

\begin{tabular}{lll}
\hline & Cagliari & Rome \\
\hline 1 Bonaria & 1 Trevi \\
2 Marina & 2 Colonna \\
3 Villanova & 3 Monti \\
4 Stampace & 4 Pigna \\
5 Castello & 5 Campitelli \\
6 San Benedetto & 6 Ripa \\
& 7 Sant'Angelo \\
& 8 Sant'Eustachio \\
& 9 Parione \\
& 10 Prati \\
& 11 Ponte \\
& 12 Borgo \\
& 13 Regola \\
& 14 Trastevere \\
& 15 Campo Marzio \\
& 16 San Saba \\
& 17 Celio \\
& 18 Testaccio \\
& 19 Castro Pretorio \\
& 20 Sallustiano \\
& 21 Ludovisi \\
& 22 Esquilino \\
\hline
\end{tabular}

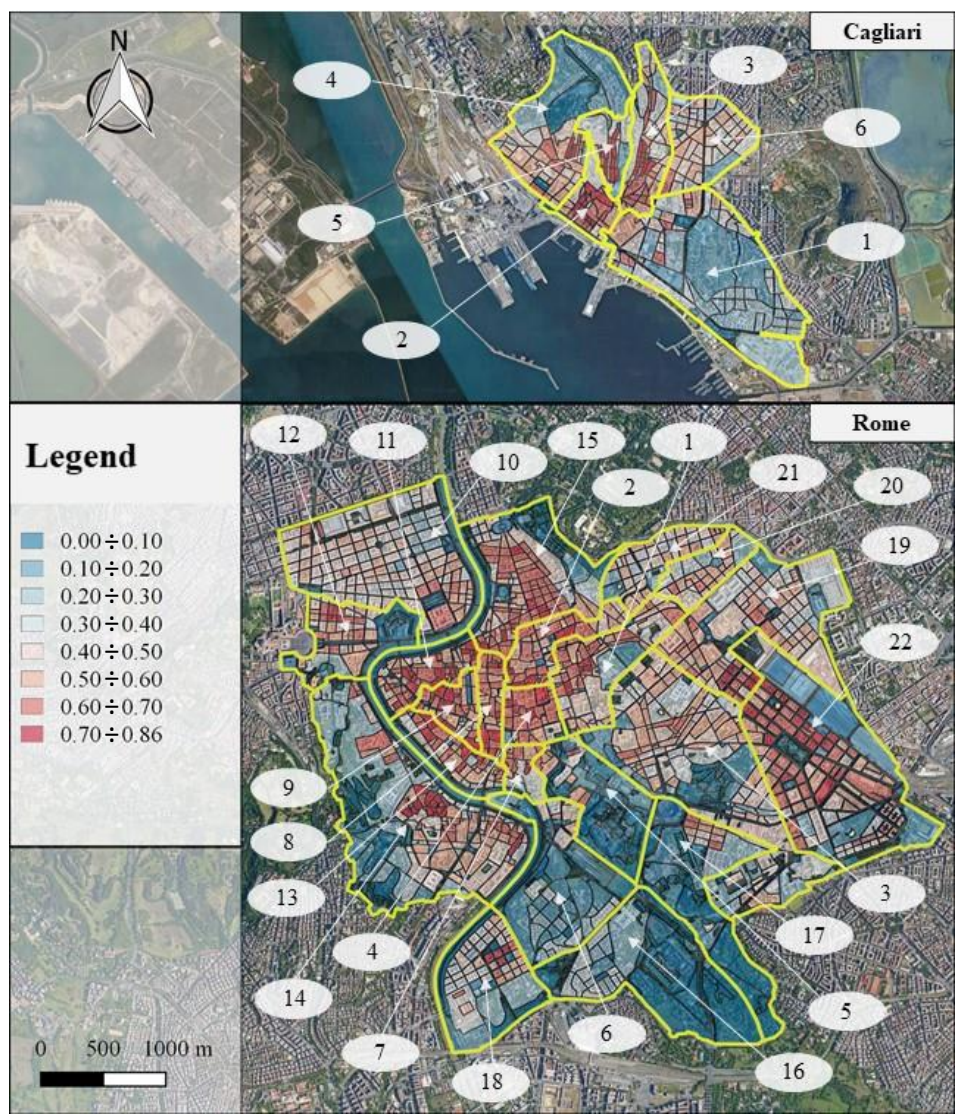

Figure 8. Spatial distribution of $\lambda_{p}$ for the two areas (street graph-based grid); the numbers identify the investigated district (see Table 1). 


\section{1. $\lambda_{p}$ and Wind Direction-Averaged $\overline{\lambda_{f}}$}

Figure 8 shows the spatial distribution of $\lambda_{p}$, computed with the adaptive street graph-based grid method, within the two investigated areas; values are grouped into 7 classes with equal range, plus one which collects the maximum values, corresponding to few elements compared to the total number (10\% for Cagliari and $2.5 \%$ for Rome). The capability of this method to identify the single building blocks should be noted. The two areas show a similar distribution of $\lambda_{p}$, with some districts (the most central ones) characterized by a denser distribution of buildings.

Figure 9 shows the probability density function for $\lambda_{p}$, computed with the adaptive street graph-based grid method. The two zones show a similar distribution, with a single peak approximately at 0.4 for Cagliari and 0.5 for Rome. This highlights a similar occupation of space in the two areas, even if slightly larger for Rome. Actually, both distributions have a strong probability peak on the zero value (not shown in Figure 9, as specified below), especially in the case of Rome, linked to large non-built (green) areas.

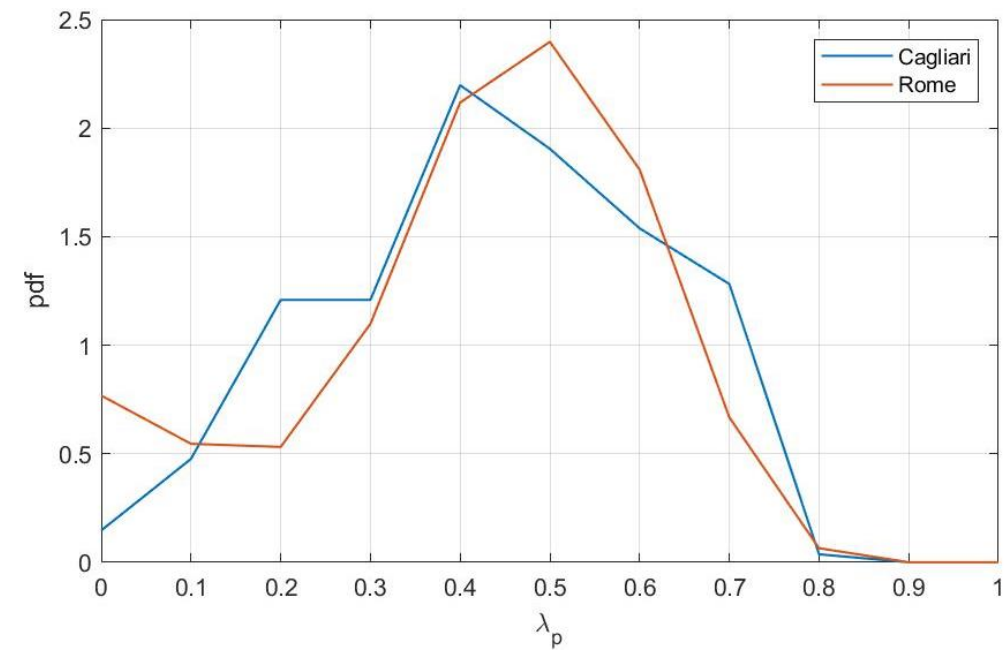

Figure 9. Probability density function of $\lambda_{p}$ for the two areas (street graph-based grid).

Figure 10 shows the spatial distribution of $\overline{\lambda_{f}}$ : values are grouped into 8 classes, plus one for maximum values (1.5\% of the elements for Cagliari and $11.6 \%$ for Rome). The maps show that values of Cagliari tend to be lower than Rome ones, properly recognizing that buildings in the investigated areas of this town tend to be higher and wider in Rome than in Cagliari.

Figure 11 shows the pdf of $\overline{\lambda_{f}}$ for the two areas: the distribution is similar, even if the peak is more pronounced and with a lower value (around 0.15) in Cagliari. Furthermore, in this case, the zero values are not shown (even it should be noticed that there is a less marked "zero peak" effect for Cagliari, in this case). Moreover, probability density functions in Figure 11 refer to a sub-sample with maximum value of 1 , because of the small number of elements that have higher values ( $0 \%$ for Cagliari and $1 \%$ for Rome). 


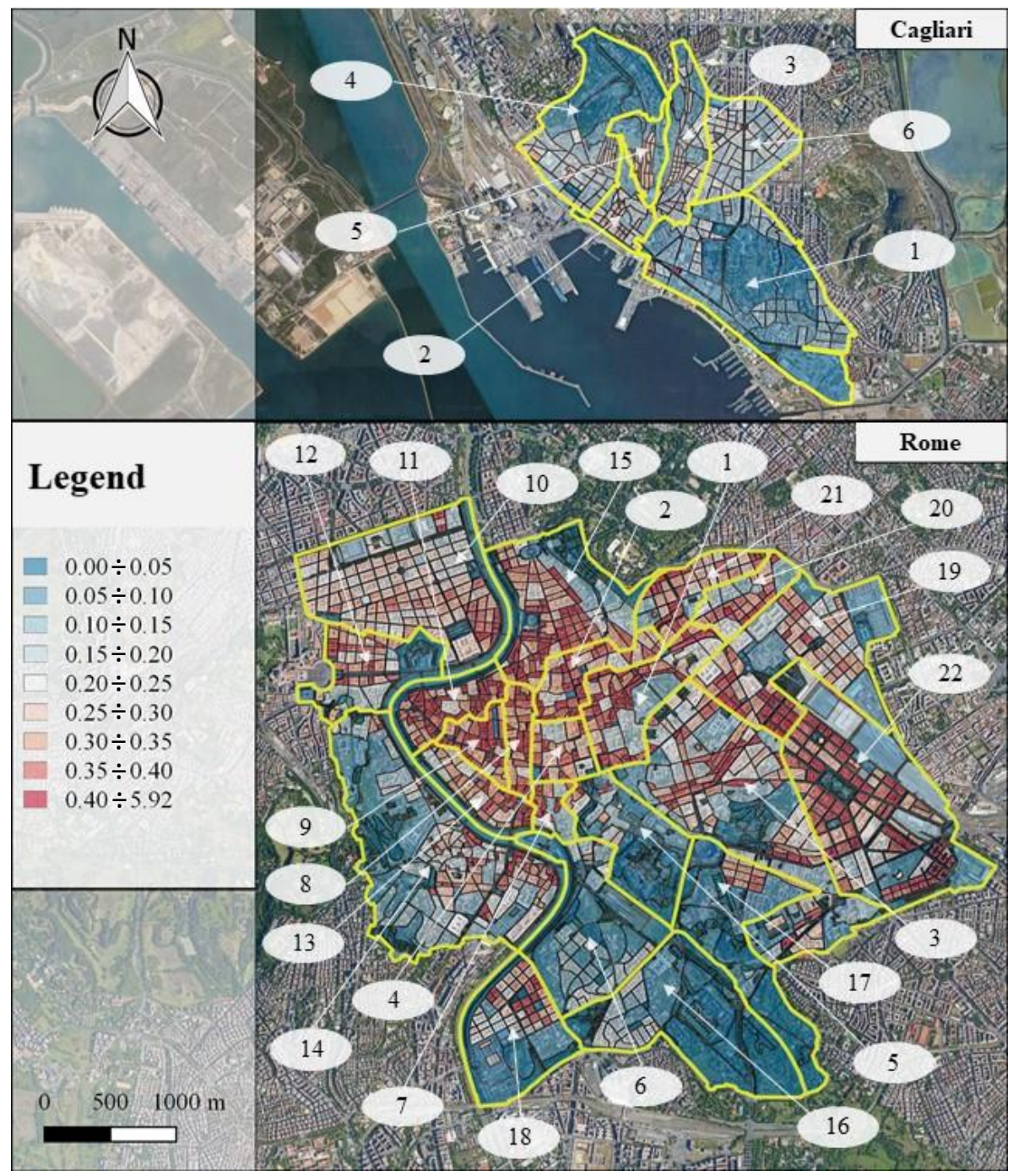

Figure 10. Spatial distribution of $\overline{\lambda_{f}}$ for the two areas (street graph-based grid); the numbers identify the investigated district (see Table 1).

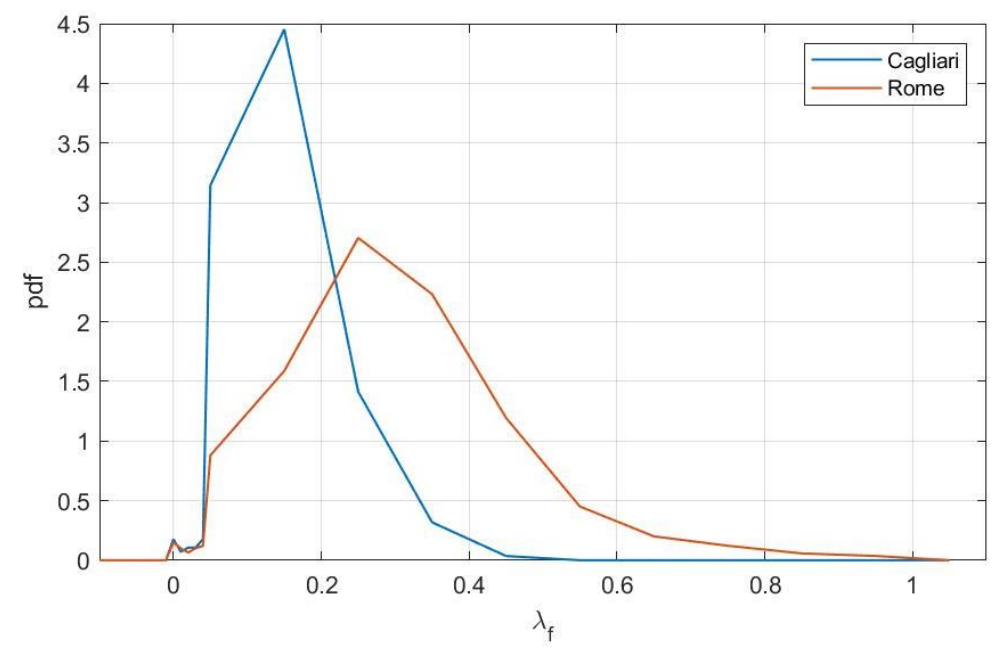

Figure 11. Probability density function of $\overline{\lambda_{f}}$ for the two areas (street graph-based grid). 
In order to compare the street graph-based grid with the regular grid, $\lambda_{p}$ and $\overline{\lambda_{f}}$ are reported in Figures 12 and 13 computed on a regular $100 \mathrm{~m}$ side grid. Comparing the two different methods, some differences can be noticed: while for $\lambda_{p}$ maximum values are quite similar when shifting between regular to street graph-based grid, the opposite happens for $\overline{\lambda_{f}}$. In fact, it can be noticed how regular grid is not able to capture higher values for $\overline{\lambda_{f}}$. This behavior can be confirmed by coming back to the pdfs in Figures 9 and 11: $\lambda_{p}$ distribution shows a similar behavior for the two areas, even if with different probability values for same ranges (conditioned by the stronger presences of smaller blocks in Cagliari area); otherwise, $\overline{\lambda_{f}}$ distribution displays a different tendency depending on the considered case study areas. This highlights the inability of regular grids to capture thinner and taller buildings contributes and should be taken into account depending on the application of morphological analysis. As before stated, because of their non-built area representation meaning, Figures 9 and 11 display pdfs obtained neglecting zero values (percentages of zero-value areas are, as percentage of number of elements, roughly $20 \%$ in Cagliari and $67 \%$ in Rome).

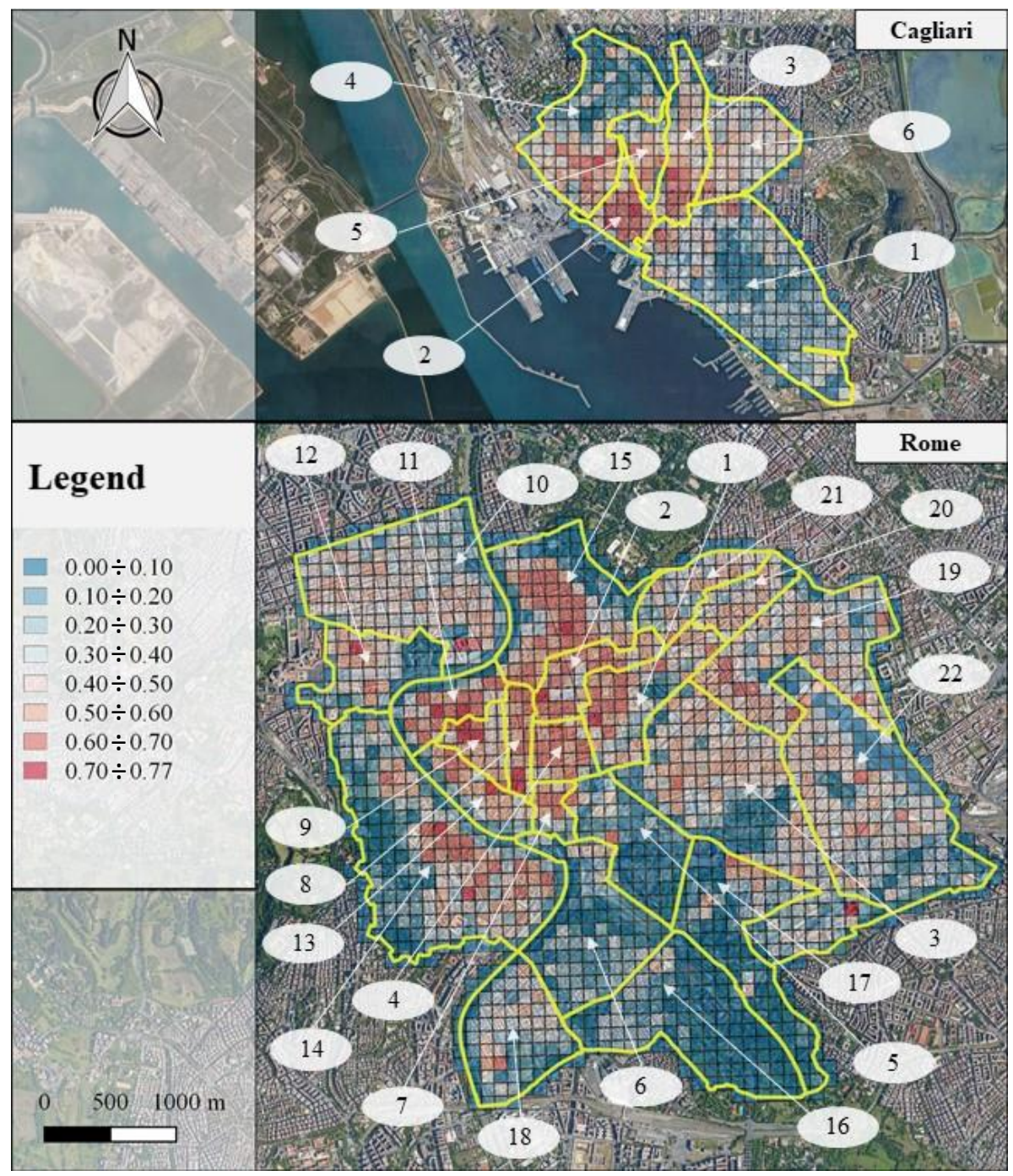

Figure 12. Spatial distribution of $\lambda_{p}$ for the two areas (regular grid); the numbers identify the investigated district (see Table 1). 


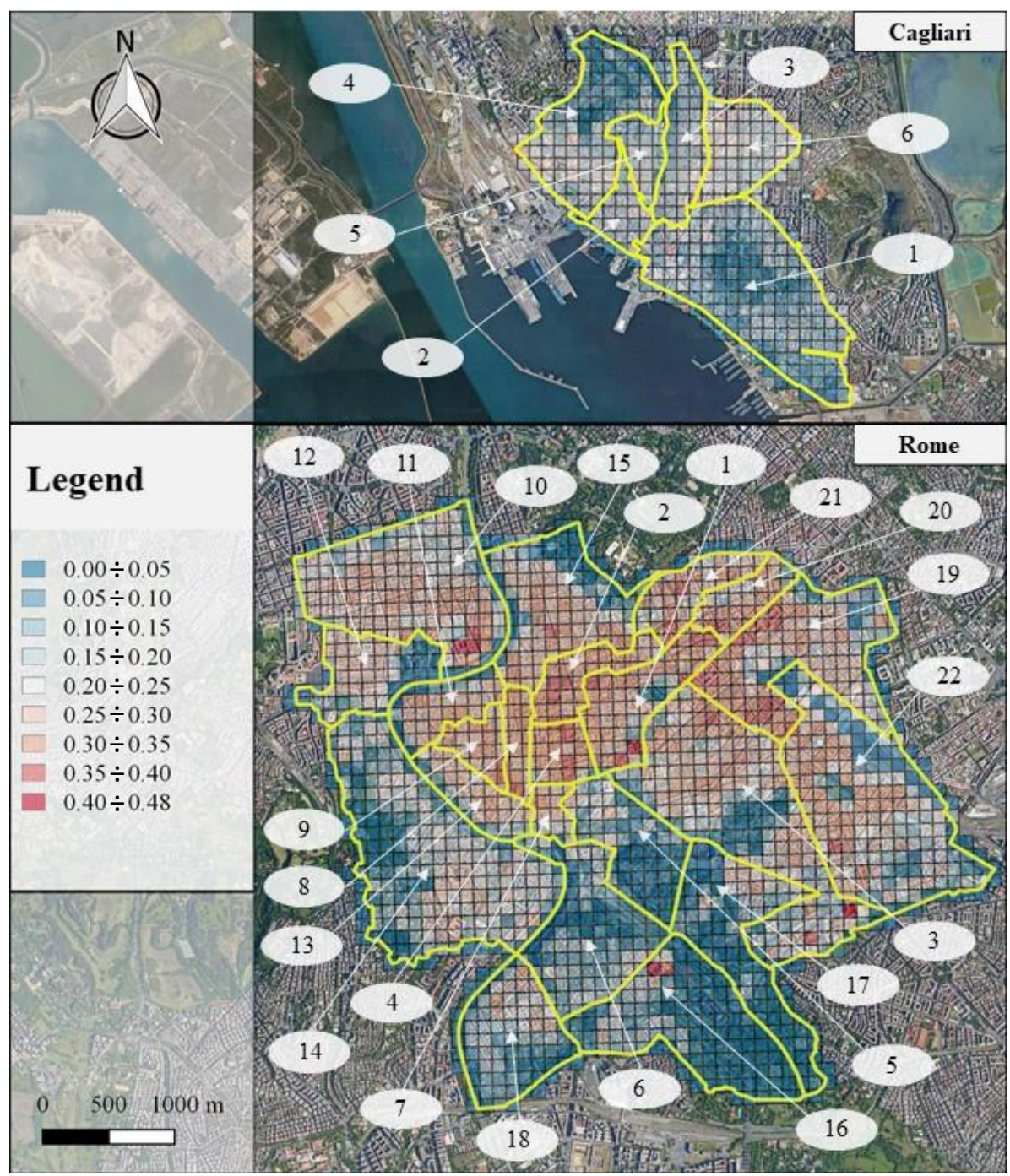

Figure 13. Spatial distribution of $\overline{\lambda_{f}}$ for the two areas (regular grid); the numbers identify the investigated district (see Table 1).

\section{2. $\lambda_{f}$ as a Function of the Wind Direction}

Figures 14 and 15 show the spatial distribution for $\lambda_{f(d i r)}$ (wind direction $320^{\circ}$ for Cagliari and $270^{\circ}$ for Rome, chosen following the criteria described in Section 2), computed with the adaptive street graph-based grid and with the regular grid, respectively: in terms of classes and maximum values. Similar considerations to the ones referred to $\overline{\lambda_{f}}$ can be made, with the regular grid tending to smooth the highest values and, consequently, to hide some of the morphometric features of the urban texture. This is more apparent when comparing the two cities: the street graph-based grid (Figure 14) is able to catch the differences between the two cities, as previously seen for $\overline{\lambda_{f}}$, while the regular grid shadows the differences, depicting very similar morphological parameters for the two cities. 


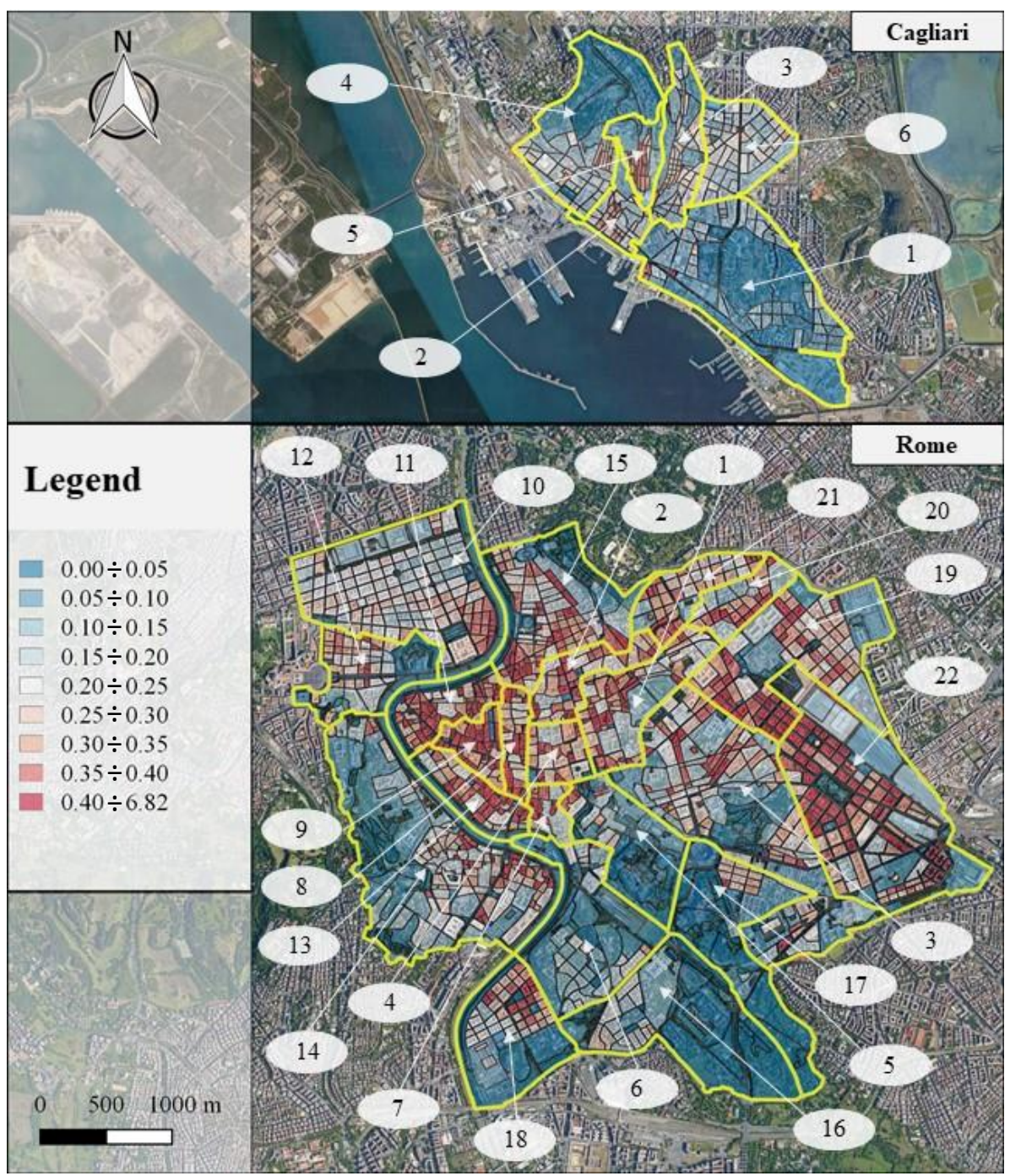

Figure 14. Spatial distribution of $\lambda_{f(d i r)}$ for the two areas (street graph-based grid); the numbers identify the investigated district (see Table 1).

Figure 16 shows $\lambda_{f(d i r)}$ considering the whole extension of the investigated areas for the two grids. It can be highlighted how the use of a different grid (regular or adaptive and street graph-based) for $\lambda_{f}$ calculation leads to remarkable differences, in terms of parameter values and distribution shape. Using a regular grid, maximum values for the parameters are always detected in the directions related to the square diagonals. Moreover, the $100 \mathrm{~m}$ regular grid tends to overestimate (in the case of Cagliari) or underestimate (in the case of Rome) the parameter values, as a consequence of the different probability distribution of the block areas in the two cities (as highlighted on Figures 9 and 11).

In Figure 17 (Cagliari) and Figure 18 (Rome), we analyze and compare results for $\lambda_{f(d i r)}$ computed on some single districts, superimposing results from regular and adaptive street graph-based grids. In addition, in this case, regular grids always finds maxima in the direction of the square diagonals. Moreover, the large differences among the values on the various districts should be kept in mind when using a single value for the morphometric characterization of large areas. 


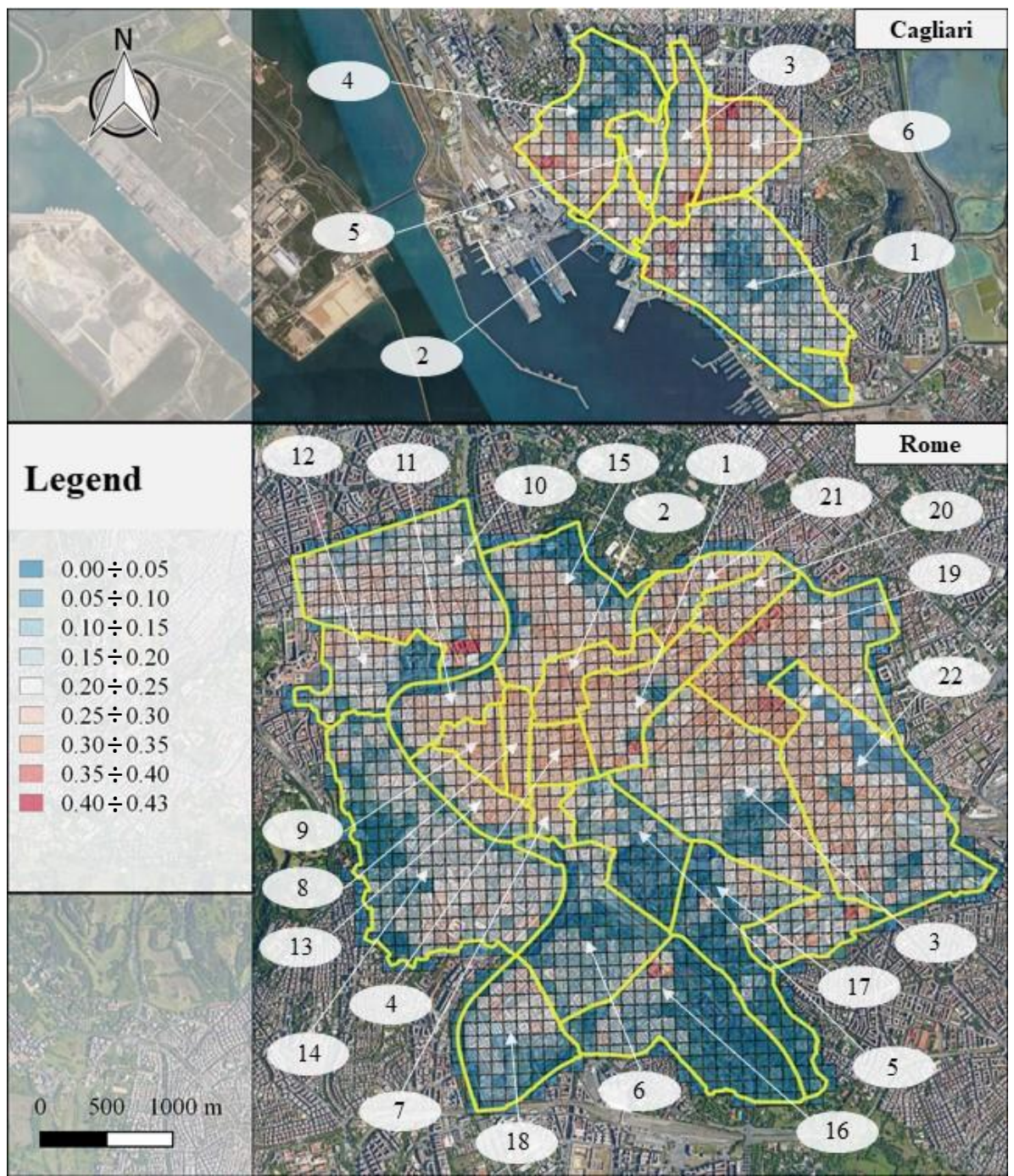

Figure 15. Spatial distribution of $\lambda_{f(d i r)}$ for the two areas (regular grid); the numbers identify the investigated district (see Table 1).
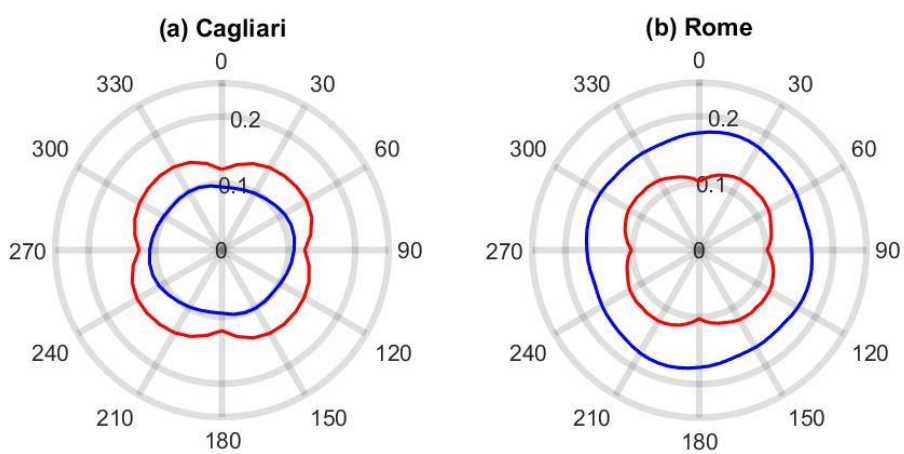

Figure 16. Directional distribution of $\lambda_{f}$ for the two areas in their whole extension; blue line indicates adaptive street graph-based grid results, red line regular grid results, with squares of $100 \mathrm{~m}$ side. 

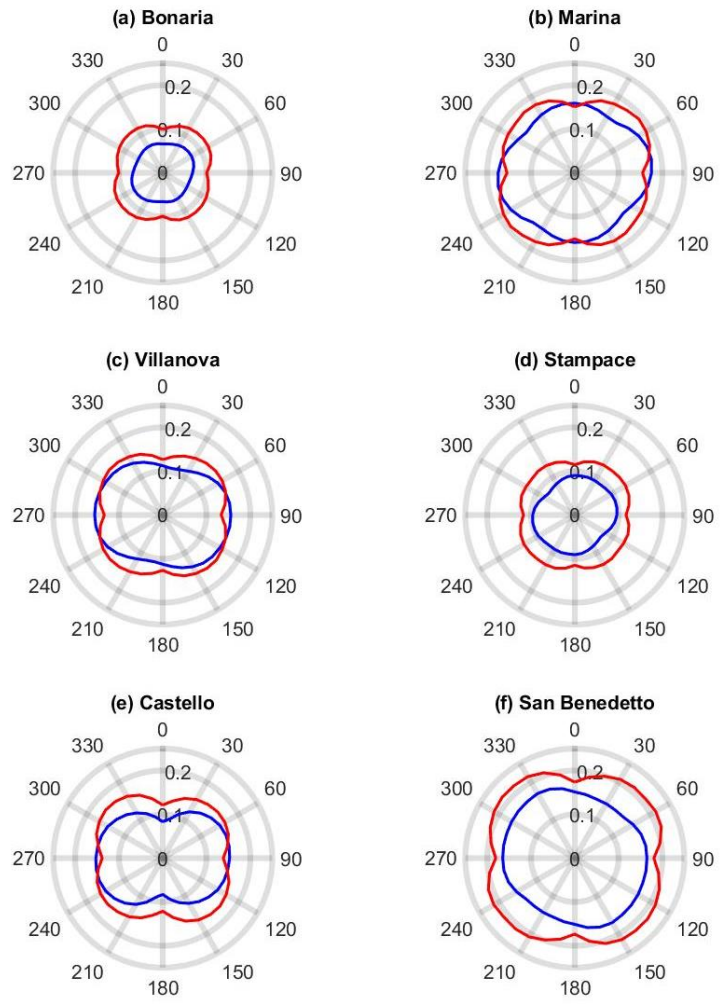

Figure 17. Directional distribution of $\lambda_{f}$ as a function of wind direction for the six Cagliari neighborhoods; blue line indicates adaptive street graph-based grid results, red line regular grid results, with squares of $100 \mathrm{~m}$ side.
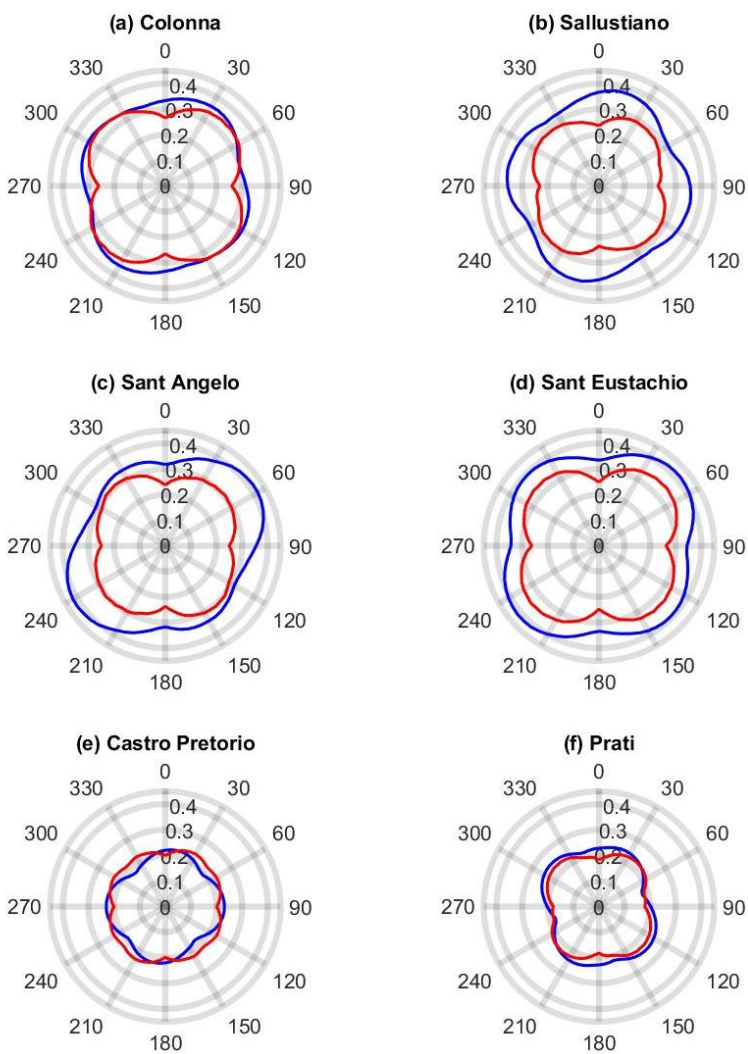

Figure 18. $\lambda_{f}$ as a function of wind direction for six chosen Rome districts; blue line indicates adaptive street graph-based grid results, red line regular grid results, with squares of $100 \mathrm{~m}$ side. 


\subsection{Aspect Ratios}

In Figures 19 and 20, the results concerning the Aspect Ratio evaluation, for canyons and buildings, respectively, are reported, for the whole areas and for some peculiar districts. In both Figures, the values have been computed with the adaptive street graph-based grid and the upper panel refers to Cagliari and the lower to Rome. The envelope curves represent the delimitation for the minimum and the maximum values of pdfs when separately considering the minimum and maximum values of the single district data; for the sake of clarity and for the readability of the Figures, not every district's pdf is reported in the Figures, but only a few representative examples.

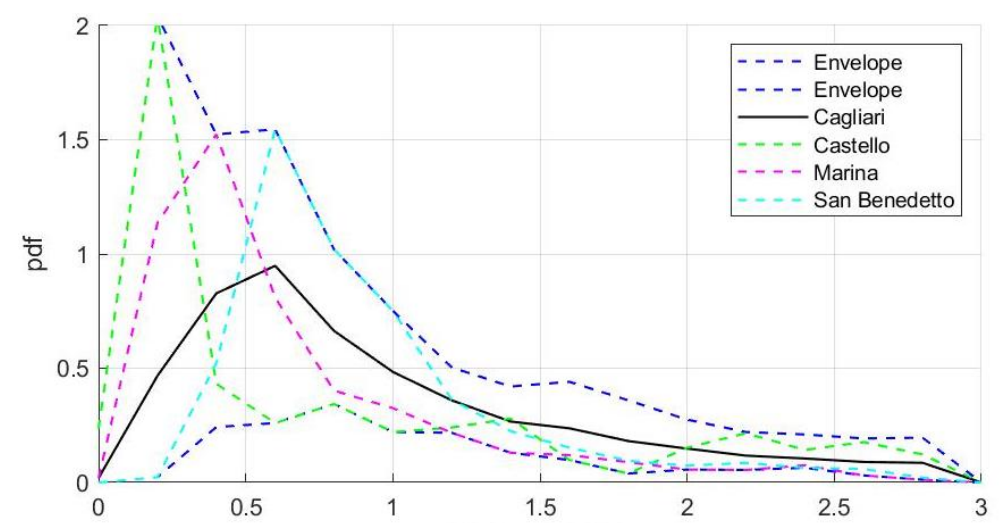

(a) Cagliari ARc

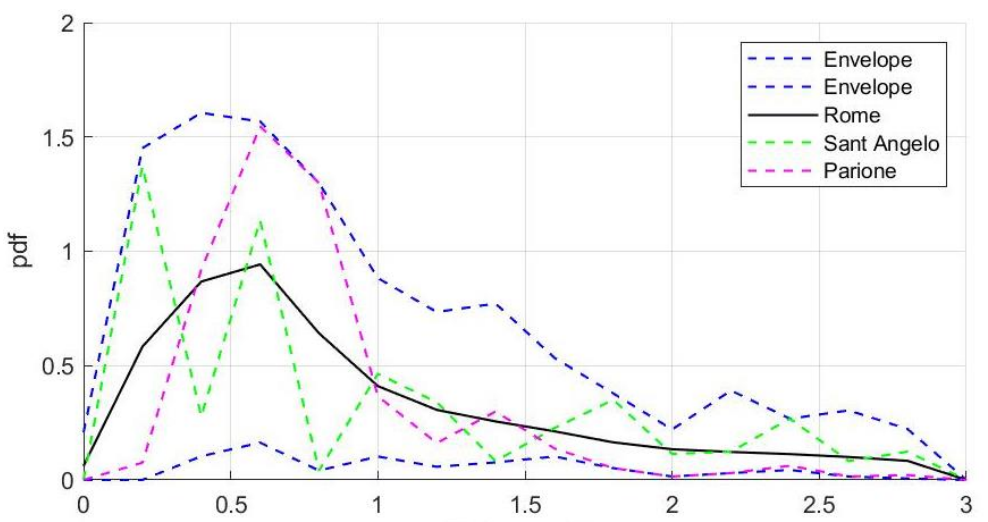

(b) Rome ARc

Figure 19. Probability density function of the $A R c$, for the two areas and peculiar neighborhood or districts, within the envelope of the total assumed values; the two envelope curves are the upper and lower ones (street graph-based grid).

A first consideration is that, when considering the whole extensions, the two curves (black lines) seem to be very similar, both in terms of characteristic values and of the shape of the distribution, and that is true for $A R b$ and even more for $A R c$. Differently, when collecting only specific district data, peaks, and peculiarity are evident, maybe suggesting a different way to represent this geometric characteristic (e.g., in case of a modal value choice). This is a remarkable fact, because it highlights the inaccuracies that can arise from the use of a single value to characterize a large urban area, in particular when studying a specific district, where the adoption of a more accurate value for the parameter may be desirable. Moreover, even when taking into account the whole areas, modal values can be detected roughly around 0.6 for $A R c$, very different from the unitary value suggested in literature in case of lack of more precise information. 


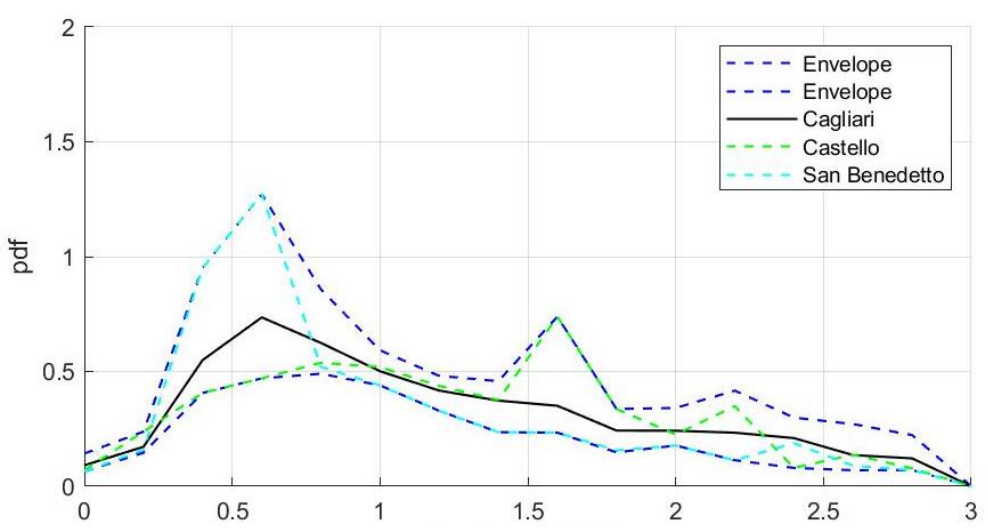

(a) Cagliari ARb

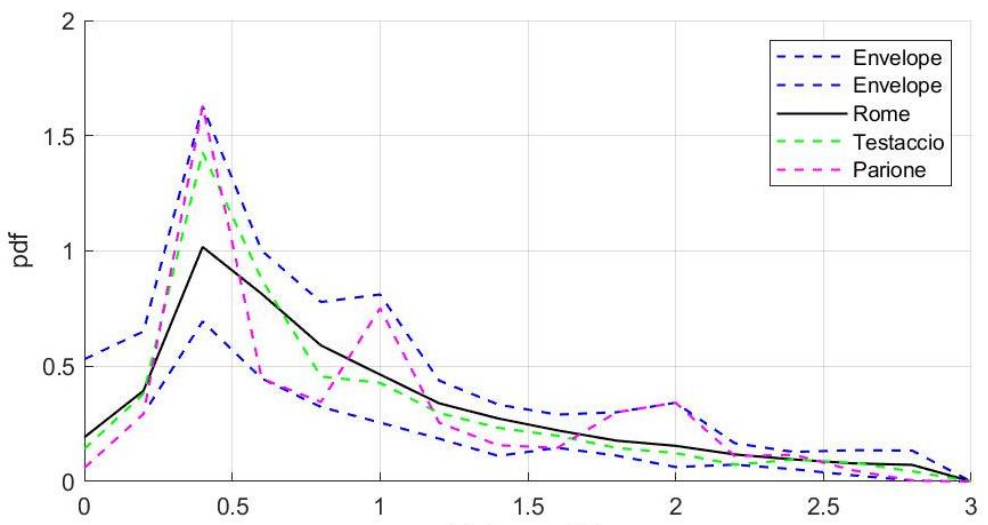

(b) Rome ARb

Figure 20. Probability density function of the $A R b$, for the two areas and peculiar neighborhood or districts, within the envelope of the total assumed values; the two envelope curves are the upper and lower ones (street graph-based grid).

\section{Conclusions}

The urban air quality modelling, both numerical and in laboratory, needs an urban geometrical parametrization as accurate as possible: in this paper, we have presented and tested a novel street graph-based method for the morphometric and urban canyons parametrization of actual urban areas. This street graph-based method allows to automatically identify the single building or block: in this way, the object of the morphometric analysis is its natural basic component, instead of the arbitrarily grouping and partially decomposing into the square of a grid. This method has been applied to two areas in the center of two Italian cities, Cagliari and Rome, which, being the result of millenniums of urban development, enclose many complex building features. The results, in terms of capability to correctly catch those complexities and of meaningfulness of the parameter values, have been discussed and compared with the ones from traditional regular grids.

Results show a better performance of the proposed method in comparison to the traditional regular grid-based methods. The analysis on the Planar Area Index $\lambda_{p}$ and the Frontal Area Index $\lambda_{f}$ (on every wind direction, averaged over all the wind directions and along the prevailing wind direction), highlights how the regular grid method tends to smooth some of the building features, in particular the ones related to building height, while the street graph-based grid method leads to a better representation of the real, urban texture features of the specific site, so achieving a more realistic representation. Moreover, the regular grid method tends to locate the maxima of $\lambda_{f}$ always along the wind directions related to the grid square diagonals.

Moreover, the adaptive grid leads to more realistic urban shape descriptions for applications that require a downscaling of the parameterization, e.g., not considering the whole city but smaller areas (such as neighborhoods or districts): this is highlighted by the 
Aspect Ratios analysis. For smaller areas, in fact, the pdfs of the Canyon Aspect Ratio, $A R b$, and of the Building Aspect Ratio, $A R c$, show a different behavior than for larger ones. In particular, pdfs computed over the whole areas depict Cagliari and Rome as two towns with similar building features, whilst the pdfs computed over the single districts are able to highlight the existing differences.

This work therefore provides a simple and rigorous urban area classification tool, very useful both for meso- and micro-scale numerical modeling, and for laboratory scale atmospheric simulations.

Further works are needed and planned: in particular, at this stage, a limitation can be related to the small number of urban areas tested, so it is necessary to test the model on a larger number of datasets, coming from different urban contexts.

Author Contributions: Conceptualization, S.F., M.G.B., and G.Q.; methodology, S.F., L.S., M.G.B. and G.Q.; data curation, L.S. and A.D.B.; writing-original draft preparation, L.S. and S.F. writingreview and editing, S.F., L.S., M.G.B., A.D.B. and G.Q. All authors have read and agreed to the published version of the manuscript.

Funding: This research was partially funded by the Fondazione di Sardegna (CUP F72F20000330007), the University of Cagliari and the Sapienza University of Rome.

Conflicts of Interest: The authors declare no conflict of interest.

\section{References}

1. LOU, C.; LIU, H.; LI, Y.; LI, Y. Research on the response of air particles $\left(\mathrm{PM}_{2.5} / \mathrm{PM}_{10}\right)$ to landscape structure: A review. Acta Ecol. Sin. 2016, 36. [CrossRef]

2. Chiri, G.M.; Achenza, M.; Canì, A.; Neves, L.; Tendas, L.; Ferrari, S. The Microclimate Design Process in Current African Development: The UEM Campus in Maputo, Mozambique. Energies 2020, 13, 2316. [CrossRef]

3. Kent, C.W.; Grimmond, S.; Gatey, D.; Hirano, K. Urban morphology parameters from global digital elevation models: Implications for aerodynamic roughness and for wind-speed estimation. Remote. Sens. Environ. 2019, 221, 316-339. [CrossRef]

4. Peng, F.; Wong, M.S.; Ho, H.C.; Nichol, J.E.; Chan, P.W. Reconstruction of historical datasets for analyzing spatiotemporal influence of built environment on urban microclimates across a compact city. Build. Environ. 2017, 123, 649-660. [CrossRef]

5. Shen, J.; Gao, Z.; Ding, W.; Yu, Y. An investigation on the effect of street morphology to ambient air quality using six real-world cases. Atmos. Environ. 2017, 164, 85-101. [CrossRef]

6. Chan, I.Y.; Liu, A.M. Effects of neighborhood building density, height, greenspace, and cleanliness on indoor environment and health of building occupants. Build. Environ. 2018, 145, 213-222. [CrossRef]

7. Shi, Y.; Xie, X.; Fung, J.C.-H.; Ng, E. Identifying critical building morphological design factors of street-level air pollution dispersion in high-density built environment using mobile monitoring. Build. Environ. 2018, 128, 248-259. [CrossRef]

8. Pelliccioni, A.; Monti, P.; Cattani, G.; Boccuni, F.; Cacciani, M.; Canepari, S.; Capone, P.; Catrambone, M.; Cusano, M.; D’Ovidio, M.C.; et al. Integrated Evaluation of Indoor Particulate Exposure: The VIEPI Project. Sustainability 2020, 12, 9758. [CrossRef]

9. European Parliament, European Union Council. On Air Quality and Clean Air in Europe; European Parliament, European Union Council: Bruxelles, Belgium, 2008.

10. Kent, C.W.; Grimmond, S.; Gatey, D.; Barlow, J.F. Assessing methods to extrapolate the vertical wind-speed profile from surface observations in a city centre during strong winds. J. Wind. Eng. Ind. Aerodyn. 2018, 173, 100-111. [CrossRef]

11. Blocken, B.J.E. Computational Fluid Dynamics for urban physics: Importance, scales, possibilities, limitations and ten tips and tricks towards accurate and reliable simulations. Build. Environ. 2015, 91, 219-245. [CrossRef]

12. Skamarock, W.C.; Klemp, B.J.; Dudhia, J.; Gill, D.O.; Barker, D.M.; Duda, M.G.; Huang, X.-Y.; Wang, W.; Powers, J.G. A Description of the Advanced Research WRF Version 3; UCAR/NCAR: Boulder, CO, USA, 2008. [CrossRef]

13. Wieringa, J. Updating the Davenport roughness classification. J. Wind. Eng. Ind. Aerodyn. 1992, 41, 357-368. [CrossRef]

14. Grimmond, C.S.B.; Oke, T.R. Aerodynamic Properties of Urban Areas Derived from Analysis of Surface Form. J. Appl. Meteorol. 1999, 38, 1262-1292. [CrossRef]

15. Martilli, A.; Clappier, A.; Rotach, M.W. An Urban Surface Exchange Parameterisation for Mesoscale Models. Bound. Layer Meteorol. 2002, 104, 261-304. [CrossRef]

16. Salamanca, F.; Martilli, A.; Tewari, M.; Chen, F. A Study of the Urban Boundary Layer Using Different Urban Parameterizations and High-Resolution Urban Canopy Parameters with WRF. J. Appl. Meteorol. Clim. 2011, 50, 1107-1128. [CrossRef]

17. Stewart, I.D.; Oke, T.R. Local Climate Zones for Urban Temperature Studies. Bull. Am. Meteorol. Soc. 2012, 93, 1879-1900. [CrossRef]

18. Demuzere, M.; Bechtel, B.; Middel, A.; Mills, G. Mapping Europe into local climate zones. PLoS ONE 2019, 14, e0214474. [CrossRef] 
19. Ching, J.; Mills, G.; Bechtel, B.; See, L.; Feddema, J.; Wang, X.; Ren, C.; Brousse, O.; Martilli, A.; Neophytou, M.; et al. WUDAPT: An Urban Weather, Climate, and Environmental Modeling Infrastructure for the Anthropocene. Bull. Am. Meteorol. Soc. 2018, 99, 1907-1924. [CrossRef]

20. Garuma, G.F. Review of urban surface parameterizations for numerical climate models. Urban Clim. 2018, 24, 830-851. [CrossRef]

21. Leo, L.S.; Buccolieri, R.; Di Sabatino, S. Scale-adaptive morphometric analysis for urban air quality and ventilation applications. Build. Res. Inf. 2018, 46, 931-951. [CrossRef]

22. Ferrari, S.; Badas, M.G.; Salvadori, L.; Garau, M.; Querzoli, G. Urban areas parametrization for CFD simulation and cities air quality analysis. Int. J. Environ. Pollut. 2019, in press. [CrossRef]

23. Ratti, C.; Di Sabatino, S.; Britter, R.; Brown, M.; Caton, F.; Burian, S. Analysis of 3-D Urban Databases with Respect to Pollution Dispersion for a Number of European and American Cities. Water Air Soil Pollut. Focus 2002, 2, 459-469. [CrossRef]

24. Franco, D.M.P.; Andrade, M.F.; Ynoue, R.Y.; Ching, J. Effect of Local Climate Zone (LCZ) classification on ozone chemical transport model simulations in Sao Paulo, Brazil. Urban Clim. 2019, 27, 293-313. [CrossRef]

25. Bechtel, B.; Alexander, P.J.; Beck, C.; Böhner, J.; Brousse, O.; Ching, J.; Demuzere, M.; Fonte, C.C.; Gál, T.; Hidalgo, J.; et al. Generating WUDAPT Level 0 data-Current status of production and evaluation. Urban Clim. 2019, 27, 24-45. [CrossRef]

26. Kaloustian, N.; Tamminga, M.; Bechtel, B. Local climate zones and annual surface thermal response in a Mediterranean city. In 2017 Joint Urban Remote Sensing Event (JURSE); IEEE: Dubai, United Arab Emirates, 2017; pp. 1-4. [CrossRef]

27. Zonato, A.; Martilli, A.; Di Sabatino, S.; Zardi, D.; Giovannini, L. Evaluating the performance of a novel WUDAPT averaging technique to define urban morphology with mesoscale models. Urban Clim. 2020, 31, 100584. [CrossRef]

28. Bechtel, B.; Alexander, P.J.; Böhner, J.; Ching, J.; Conrad, O.; Feddema, J.; Mills, G.; See, L.; Stewart, I. Mapping Local Climate Zones for a Worldwide Database of the Form and Function of Cities. IJGI 2015, 4, 199-219. [CrossRef]

29. Facing COVID-19 Challenges with Our Customers and Partners. Available online: https://www.ansys.com (accessed on 14 December 2020).

30. Di Bernardino, A.; Monti, P.; Leuzzi, G.; Querzoli, G. Pollutant fluxes in two-dimensional street canyons. Urban Clim. 2018, 24, 80-93. [CrossRef]

31. Garau, M.; Badas, M.G.; Ferrari, S.; Seoni, A.; Querzoli, G. Turbulence and Air Exchange in a Two-Dimensional Urban Street Canyon Between Gable Roof Buildings. Bound. Layer Meteorol. 2017, 167, 123-143. [CrossRef]

32. Badas, M.G.; Garau, M.; Querzoli, G. How gable roofs change the mechanisms of turbulent vertical momentum transfer: A LES study on two-dimensional urban canyons. J. Wind. Eng. Ind. Aerodyn. 2021, 104432. [CrossRef]

33. Ferrari, S.; Badas, M.G.; Garau, M.; Seoni, A.; Querzoli, G. The air quality in narrow two-dimensional urban canyons with pitched and flat roof buildings. Int. J. Environ. Pollut. 2017, 62, 22.

34. Garau, M.; Badas, M.G.; Ferrari, S.; Seoni, A.; Querzoli, G. Air Exchange in urban canyons with variable building width: A numerical LES approach. Int. J. Environ. Pollut. 2019, 65, 103. [CrossRef]

35. Badas, M.G.; Ferrari, S.; Garau, M.; Seoni, A.; Querzoli, G. On the Flow Past an Array of Two-Dimensional Street Canyons Between Slender Buildings. Bound. Layer Meteorol. 2020, 174, 251-273. [CrossRef]

36. Wind Roses. Available online: https://mesonet.agron.iastate.edu/sites/windrose.phtml?station=LIRF\&network=IT_ASOS (accessed on 8 December 2020).

37. Available online: https: / / www.mareografico.it/?session=0S25916556316880878488656970\&syslng=ita\&sysmen=-1\&sysind=-1 \&syssub=-1\&sysfnt=0\&code=STAZ\&idst=1Q\&idreq=3@3@2\&set=date (accessed on 1 December 2020).

38. Salvadori, L.; Badas, M.G.; Garau, M.; Bernardino, A.D.; Pini, A.; Querzoli, G.; Ferrari, S. Similar urbanistic typologies and morpho-metric parametrization: Analysis of a possible date of construction based classification. In Proceedings of the 19th International Conference on Harmonisation within Atmospheric Dispersion Modelling for Regulatory Purposes, Harmo 2019, Bruges, Belgium, 3-6 June 2019.

39. Ratti, C.; Di Sabatino, S.; Britter, R. Urban texture analysis with image processing techniques: Winds and dispersion. Theor. Appl. Clim. 2006, 84, 77-90. [CrossRef]

40. Di Sabatino, S.; Leo, L.S.; Cataldo, R.; Ratti, C.; Britter, R.E. Construction of Digital Elevation Models for a Southern European City and a Comparative Morphological Analysis with Respect to Northern European and North American Cities. J. Appl. Meteorol. Clim. 2010, 49, 1377-1396. [CrossRef] 